\title{
ÍNDICE DE DESCONFORTO OSTEOMUSCULAR DE PARTICIPANTES DO PROGRAMA SAÚDE INTEGRAL DO TRABALHADOR - SITRA DA FCT/UNESP
}

\author{
Elaine Aparecida Lozano da Silva, Letícia Endsfeldz Teixeira, Valeria Andrea Alegria Larrua, Maria \\ Rita Masselli, Célia Aparecida Stellutti Pachioni
}

Curso de Fisioterapia da Universidade Estadual Paulista Júlio de Mesquita Filho - Faculdade de Ciências e Tecnologia FCT/UNESP. E-mail: elaine_1060@hotmail.com

\section{RESUMO}

A promoção de saúde no ambiente de trabalho melhora a relação entre vida saudável e aumento da produtividade. $O$ homem passou a realizar sua função em longos períodos na mesma posição, causando-lhe desconfortos. O objetivo foi avaliar a ocorrência de desconfortos osteomusculares dos funcionários da FCT/UNESP inscritos no Programa Saúde Integral do Trabalhador - SITRA. Trata-se de um estudo transversal com 46 funcionários com idade média de 41 anos \pm 8,96 anos. Para avaliar os sintomas osteomusculares foi utilizado o questionário nórdico. Os resultados mostraram que $91,3 \%$ dos trabalhadores relataram algum tipo de desconforto osteomuscular nos últimos doze meses, $59,1 \%$ nos últimos sete dias e 30,4\% tiveram que evitar/reduzir suas atividades. Dessa forma, constata-se que o programa SITRA se faz necessário para diminuir a prevalência de sintomas osteomusculares e proporcionar modificações positivas na qualidade de vida dos funcionários.

Palavras-chave: Saúde do trabalhador, Atividade física, Desconforto osteomuscular, Qualidade de vida, Prevenção.

\section{INTRODUÇÃO}

Estudos sobre a promoção de saúde no local de trabalho têm quantificado a relação entre boa saúde e aumento de produtividade. A produtividade do funcionário está diretamente ligada com sua condição física, mental, espiritual e social. Estudos revelam que $40 \%$ dos afastamentos são motivados por pequenas doenças e mal-estar, as quais podem ser evitadas por um bom condicionamento físico. E ainda, $20 \%$ dos trabalhadores brasileiros têm problemas como obesidade, sedentarismo e estresse (SANTOS, VAJDA, 2007).

Nos últimos anos tem-se observado um aumento no índice de sobrepeso e obesidade em quase todos os países, considerado este um dos principais problemas de saúde na população. Dentre os fatores que predispõem a obesidade, podemos citar a relação entre o consumo energético proveniente do fornecimento de energia composto pela dieta e a demanda energética relacionada com prática de atividades físicas (MENDONÇA, ANJOS, 2004). Os maus hábitos alimentares e a inatividade física contribuem para o aparecimento de disfunções orgânicas, levando implicações à saúde do indivíduo, sendo assim a atividade física é considerada um dos principais meios de intervenção na prevenção de disfunções na saúde física (JUNIOR, 2001). 
No Brasil, as alterações músculoesqueléticas mais encontradas nos funcionários, que estão relacionadas com o trabalho tais como os distúrbios osteomusculares relacionados ao trabalho (DORT) são classificadas como a segunda causa de afastamento do trabalho, sendo este o principal agravo à saúde entre as doenças ocupacionais no país (ABRAHÃO, DUARTE, 2007). Estudos epidemiológicos revelam que mais de quatro milhões de brasileiros apresentam tratamentos médico e psicológico devido à presença de dores osteomusculares em consequência de posturas inadequadas e sobrecarga da jornada de trabalho (SANTOS et al., 2007).

Com base na literatura, a prática regular de exercício físico traz efeitos benéficos para os distúrbios do sono, aos aspectos psicológicos, aos transtornos de humor, como a ansiedade e a depressão, e aos aspectos cognitivos, como a memória e a aprendizagem (MELLO et al., 2005). Já a inatividade física e um estilo de vida sedentário estão relacionados a fatores de risco para o desenvolvimento de dores e certas condições patológicas, tais como alterações cardiovasculares e metabólicas (SILVA et al., 2010).

A atividade física é uma forma de lazer e de restaurar a saúde dos efeitos nocivos que a rotina estressante do trabalho nos traz, beneficiando assim o praticante desde o perfil lipídico até a melhora da autoestima, sendo evidenciado melhora na qualidade de vida em todos os aspectos (SILVA et al., 2010). Os exercícios são realizados no próprio local de trabalho, contribuindo para um melhor condicionamento, desempenho físico, concentração e um melhor posicionamento frente aos postos de trabalho (LEAL, MEJIA, 2012).

A ginástica laboral é a combinação de atividades físicas que englobam alongamentos, relaxamento muscular e flexibilidade, com duração em média de dez a quinze minutos e com enfoque nas musculaturas mais sobrecarregadas durante a jornada de trabalho. Esta intervenção pode ser destacada como um método efetivo na prevenção da LER/DORT e de outras doenças ocupacionais (LEAL, MEJIA, 2012).

Sendo assim como consequência do estresse ocasionado em alguns postos de trabalho, o indivíduo pode apresentar dores agudas e até mesmo dor crônica considerada um dos principais problemas na saúde pública, acarretando sérios prejuízos pessoais e econômicos para a população. Dentre as implicações provenientes da dor crônica podemos citar a irritabilidade, perda de concentração e comprometimento da qualidade de vida, no bom desempenho profissional e vida social (KRELING, CRUZ, PIMENTA, 2006). Dessa forma, o objetivo deste estudo foi avaliar a ocorrência de sintomas osteomusculares nos funcionários da Faculdade de Ciências e 
Tecnologia da UNESP - Campus de Presidente Prudente inscritos no Programa Saúde Integral do Trabalhador (SITRA) por meio do questionário Nórdico.

\section{METODOLOGIA}

Trata-se de um estudo transversal com 46 funcionários da FCT UNESP - Campus de Presidente Prudente que realizam regularmente o Programa SITRA. Destes 38 do gênero feminino $(82,6 \%)$ e oito do gênero masculino $(17,4 \%)$, com idade média e desvio padrão de 41 anos $\pm 8,96$ anos, respectivamente. Este estudo científico foi aprovado pelo Comitê de Ética no Processo $\mathrm{n}^{\circ}$ 43/2010.

O programa SITRA se baseia no tripé: hidratação; reeducação alimentar e atividade física em várias modalidades. São realizadas palestras para conscientizar os funcionários da importância de uma alimentação adequada, boa hidratação e da realização de atividades físicas regulares. Os exercícios são realizados no próprio local de trabalho, com alongamentos, equilíbrio, coordenação motora, fortalecimento e consciência corporal para melhorar a disposição ao trabalho, relaxar corpo e mente, ativar a circulação, reduzir o estresse e melhorar postura.

Os desconfortos osteomusculares foram avaliados utilizando o questionário nórdico de sintomas osteomusculares que consiste em escolhas múltiplas ou binárias quanto à ocorrência de sintomas nas diversas regiões anatômicas mais comumente acometidas. $\mathrm{O}$ respondente relatou a ocorrência dos sintomas considerando os 12 meses e/ou os sete dias precedentes à entrevista, bem como a ocorrência de redução das atividades rotineiras no último ano (PINHEIRO, TRÓCCOLIA, CARVALHO, 2002).

\section{RESULTADOS}

Os resultados mostraram que nos últimos doze meses as regiões menos acometidas por sintomas osteomusculares foram os cotovelos com $80,4 \%$, os antebraços com $76 \%$ e braços com $54 \%$, ocorrendo raramente desconfortos. Já a região lombar com 21,73\%, o quadril e MMII com 19,56\%, os ombros com $19,70 \%$ e pescoço/cervical com $17,30 \%$ apresentaram predominância dos desconfortos osteomusculares (Tabela 1). 
Tabela 1. Frequência de desconfortos osteomusculares por região anatômica nos últimos 12 meses em funcionários participantes do SITRA

\begin{tabular}{lcccc}
\hline & Não & Raramente & Com Frequência & Sempre \\
\hline Pescoço e cervical & $26 \%$ & $46 \%$ & $17,3 \%$ & $10,8 \%$ \\
Ombros & $36,9 \%$ & $34,7 \%$ & $19,5 \%$ & $8,6 \%$ \\
Braços & $54 \%$ & $28,2 \%$ & $15 \%$ & $2,1 \%$ \\
Cotovelos & $80,4 \%$ & $15 \%$ & $4,3 \%$ & $0 \%$ \\
Antebraço & $76 \%$ & $17,3 \%$ & $6,5 \%$ & $0 \%$ \\
Punhos & $52 \%$ & $30,4 \%$ & $13 \%$ & $4,3 \%$ \\
Dorsal & $39,1 \%$ & $36,9 \%$ & $15 \%$ & $9 \%$ \\
Lombar & $22 \%$ & $39 \%$ & $21,7 \%$ & $17,3 \%$ \\
Quadril e MMII & $43,4 \%$ & $26 \%$ & $19,5 \%$ & $11 \%$ \\
\hline
\end{tabular}

Em relação à localização anatômica dos sintomas osteomusculares relacionados aos períodos dos últimos doze meses e sete dias, prevalece a região lombar com $69,5 \%$ e $36,9 \%$, respectivamente, seguida do pescoço/cervical com 60,8 e $36,9 \%$ e ombros com $54,3 \%$ e $34,7 \%$. Já em relação a funcionários que evitaram ou reduziram suas atividades, a região que se destacou também foi a lombar com 15,2\%, além dos ombros e dos quadris com 10,8\% (Tabela 2).

Tabela 2. Freqüência de desconfortos osteomusculares referidos por funcionários participantes do SITRA, por região anatômica, nos últimos doze meses, nos últimos sete dias e redução das atividades devido a essas condições.

\begin{tabular}{lccc}
\hline & 12 meses & 7 dias & $\begin{array}{c}\text { Evitar/ reduzir } \\
\text { atividades }\end{array}$ \\
\hline Pescoço & $60,8 \%$ & $36,9 \%$ & $8,6 \%$ \\
Ombros & $54,3 \%$ & $34,7 \%$ & $10,8 \%$ \\
Cotovelos & $15,2 \%$ & $8,6 \%$ & $8,6 \%$ \\
Antebraço & $6,5 \%$ & $4,3 \%$ & $0 \%$ \\
Punhos & $39,1 \%$ & $23,9 \%$ & $8,6 \%$ \\
Dorsal & $41,3 \%$ & $13 \%$ & $6,5 \%$ \\
Lombar & $69,5 \%$ & $36,9 \%$ & $15,2 \%$ \\
Quadris e/ou coxas & $34,7 \%$ & $21,7 \%$ & $10,8 \%$ \\
Joelhos & $21,7 \%$ & $10,8 \%$ & $8,6 \%$ \\
Tornozelos & $23,9 \%$ & $13 \%$ & $8,6 \%$ \\
\hline
\end{tabular}

De acordo com os resultados do questionário nórdico, pode-se inferir que $91,3 \%$ dos trabalhadores relataram algum tipo de sintoma osteomuscular (dor, desconforto ou dormência) nos últimos doze meses e 59,1\% nos últimos sete dias, sendo que 30,4\% tiveram que evitar atividades normais devido ao problema. A presença desses desconfortos nos períodos citados acima teve como predominância a região lombar, os ombros e a região cervical/pescoço. 


\section{DISCUSSÃO}

O presente estudo avaliou a ocorrência de sintomas osteomusculares em funcionários inscritos no Programa SITRA. Esses trabalhadores relataram algum tipo de sintoma osteomuscular nas diversas regiões do corpo, tendo predominância nas regiões lombares, cervicais e nos ombros.

Coury, Moreira, Dias (2009) relatam que os distúrbios musculoesqueléticos têm associação com a biomecânica e postura adquirida durante as atividades e trabalho diário. A dor é o sintoma mais comum apresentado podendo evoluir para uma dor crônica ou perda de função. A incidência de dor no ombro e pescoço tem ocorrido com maior frequência, porém não ultrapassam a dor na região lombar.

O estudo realizado por Melo et al (2013), constatou a presença de sintomas osteomusculares na região lombar (45\%), ombros (42\%) e punhos (28\%) como prevalência. Esse estudo foi composto por 44 trabalhadores do setor administrativo, sendo que $75 \%$ relataram presença álgica nos últimos doze meses, $27,2 \%$ nos últimos sete dias e $25 \%$ dos trabalhadores tiveram afastamento do trabalho, vindo de encontro aos nossos resultados.

De acordo com o estudo de Picoloto e Silveira (2008) pode-se inferir que $75,2 \%$ dos trabalhadores relataram algum tipo de sintoma osteomuscular nos últimos doze meses, 53,3\% nos últimos sete dias, sendo que 38,5\% já tiveram afastamento devido ao problema. Em relação à localização anatômica do sintoma osteomuscular relacionado aos períodos de últimos doze meses e sete dias, também neste estudo prevaleceu a região lombar, seguida pelos ombros e cervical.

Machado (2008) também obteve valores que vão de encontro com os nossos resultados. Em relação à localização anatômica do sintoma osteomuscular no período dos últimos doze meses, resultaram em 59\% para dor na região lombar, 39\% punhos/mãos, 27\% pescoço e ombros. Segundo Mozzini, Polese, Beltrame (2008) a alta prevalência de dor lombar se deve à má postura, falta de condicionamento físico e sobrecarga da região. Com relação à dor na cervical e ombros a incidência se deve a movimentos de inclinação da cabeça que provocam grande tensão muscular.

Segundo o estudo de Bergamaschi, Deutsch e Ferreira (2002) o programa de ginástica laboral pode trazer benefícios físicos na qualidade de vida do trabalhador, reduzindo a presença de dores localizadas, diminuição do estresse mental, melhoria do humor, e motivação social com os demais funcionários pertencentes ao campo de trabalho.

O ambiente de trabalho não deve ser um lugar que reflete o aparecimento de patologias e problemas emocionais, porém há circunstâncias que promovem desconfortos e problemas de saúde. Devido à falta de adequação do local de trabalho às normas de ergonomia, há um aumento 
no aparecimento de distúrbios musculoesqueléticos, mas a realização de ginástica laboral durante as atividades reduzem a sintomatologia e promovem o bem-estar físico e mental dos profissionais (MOZZINI, POLESE, BELTRAME, 2008).

\section{CONCLUSÃO}

Os desconfortos osteomusculares ainda são muito frequentes em trabalhadores, sendo a região lombar, cervical/pescoço e ombros predominantes. Acreditamos que as atividades realizadas no Programa Saúde Integral do Trabalhador (SITRA) podem trazer modificações positivas na qualidade de vida dos funcionários, diminuindo a presença de desconfortos osteomusculares e conseqüentemente o absenteísmo.

\section{REFERÊNCIAS}

1. ABRAHÃO, P. N; DUARTE, M. S. Incidência e prevalência de dores e funcionários administrativos de uma instituição particular de ensino superior do município do Rio de Janeiro, 2007.

2. BERGAMASCHI, E. C.; DEUTSCH, S.; FERREIRA, E. P. Ginástica Laboral: Possíveis implicações para as esferas física, psicológica e social. Atividade Física e Saúde. Pelotas, v. 7, n. 3, p.23-29, 2002.

3. COURY, H. J. C. G.; MOREIRA, R. F. C.; DIAS, N. B. Efetividade do exercício físico em ambiente ocupacional para controle da dor cervical, lombar e do ombro: uma revisão sistemática. Rev. Bras. Fisioterapia, v. 13, n. 6, p. 461-79, nov./dez. 2009. http://dx.doi.org/10.1590/S141335552009000600002

4. JUNIOR, J. C. F. Associação entre nível de atividade física, composição da dieta e gordura corporal em adultos. Núcleo de pesquisa em atividade Física e Saúde. NUPAF, v. 6, n. 3, 2001.

5. KRELING, M. C. G. D.; CRUZ, D. A. L. M.; PIMENTA, C.A.M. Prevenção de dor crônica em adultos. Rev Bras Enferm, v. 59, n. 4, p. 509-13, jul./ago., 2006.

6. LEAL, L. F. C.; MEJIA, D. P. M. Ginástica Laboral como ferramenta de prevenção para a melhoria da qualidade de vida. Maio 2012.

7. MACHADO, M. R. M. L. Proposta de um conjunto de exercícios de ginástica laboral, com respostas ás principais lesões músculo-esquelética relacionadas ao trabalho. Monografia, Universidade do Porto, 2008.

8. MELO, V. F. et al. Incidência de distúrbios osteomusculares relacionados ao trabalho (DORT), em trabalhadores do setor administrativo do instituto nacional de metrologia, qualidade e tecnologia (INMETRO), Rio de Janeiro, Brasil. Revista Saúde Física \& Mental- UNIABEU, v. 2 n.1, Jan./Jul., 2013.

9. MELLO, M. T.; et al. O exercício físico e os aspectos psicobiológicos. Rev. Bras. Med. Esporte, v. 11, n. 3, mai/jun, 2005. http://dx.doi.org/10.1590/S1517-86922005000300010 
10. MENDONÇA, C. P.; ANJOS, L. A. Aspectos das práticas alimentares e da atividade física como determinantes do crescimento do sobrepeso/obesidade no Brasil. Caderno Saúde Pública, Rio de Janeiro, v. 20, n. 3, p. 698-709, mai/jun, 2004.

11. MOZZINI, C. B.; POLESE, J. C.; BELTRAME, M. R. Prevalência de sintomas osteomusculares em trabalhadores de uma empresa de embalagens metálicas de Passo Fundo - RS. Rev. Bras. em Promoção da Saúde, v. 21, n. 2, p. 92-97, 2008. http://dx.doi.org/10.5020/18061230.2008.p92

12. PICOLOTO, D.; SILVEIRA, E. Prevalência de sintomas osteomusculares e fatores associados em trabalhadores de uma indústria metalúrgica de Canoas - RS. Ciência \& Saúde Coletiva, v. 13, n. 2, p. 507-516, 2008. http://dx.doi.org/10.1590/S1413-81232008000200026

13. PINHEIRO, F. A.; TRÓCCOLIA, B. T.; CARVALHO, C. V. Validação do Questionário Nórdico de Sintomas Osteomusculares como medida de morbidade. Rev. Saúde Pública, v. 36, n. 3, p. 307-12, 2002. http://dx.doi.org/10.1590/S0034-89102002000300008

14. SANTOS, A. F.; et al. Benefício da Ginástica Laboral na prevenção dos distúrbios osteomusculares relacionados ao trabalho. Arq. Ciênc. Saúde Unipar, Umuarama, v.11, n.2, p. 107-113, maio/ago, 2007.

15. SANTOS, F. A. T.; VAJDA, F. R. Estudo sobre a preocupação das empresas com a saúde dos funcionários. Revista Ciências do Ambiente On-Line, v. 3, n. 1, fev, 2007.

16.SILVA, R. S.; et al. Atividade física e qualidade de vida. Ciência \& Saúde Coletiva, v. 15, n. 1, p. 115-120, 2010. http://dx.doi.org/10.1590/S1413-81232010000100017 